\title{
Plant diversity represents the prevalent determinant of soil fungal community structure across temperate grasslands in northern China
}

\author{
Yong-Liang Chen ${ }^{\mathrm{a}, \mathrm{b}, 1}$, Tian-Le $\mathrm{Xu}^{\mathrm{a}, \mathrm{c}, 1}$, Stavros D. Veresoglou ${ }^{\mathrm{d}, \mathrm{e}}$, Hang-Wei Hu${ }^{\mathrm{a}, \mathrm{f}}$, \\ Zhi-Peng Hao ${ }^{a}$, Ya-Jun Hu ${ }^{a}$, Lei Liu ${ }^{a}$, Ye Deng ${ }^{g}$, Matthias C. Rillig ${ }^{\text {d, e }}$, Bao-Dong Chen ${ }^{\text {a, c, * }}$ \\ a State Key Laboratory of Urban and Regional Ecology, Research Center for Eco-Environmental Sciences, Chinese Academy of Sciences, Beijing, China \\ b State Key Laboratory of Vegetation and Environmental Change, Institute of Botany, Chinese Academy of Sciences, Beijing, China \\ ${ }^{\mathrm{c}}$ University of Chinese Academy of Sciences, Beijing, China \\ ${ }^{\mathrm{d}}$ Freie Universität Berlin-Institut für Biologie, Dahlem Center of Plant Sciences, Plant Ecology, Berlin, Germany \\ e Berlin-Brandenburg Institute of Advanced Biodiversity Research, Berlin, Germany \\ ${ }^{\mathrm{f}}$ Faculty of Veterinary and Agricultural Sciences, The University of Melbourne, Melbourne, VIC, Australia \\ ${ }^{g}$ CAS Key Laboratory of Environmental Biotechnology, Research Center for Eco-Environmental Sciences, Chinese Academy of Sciences, Beijing, China
}

\section{A R T I C L E I N F O}

\section{Article history:}

Received 11 November 2016

Received in revised form

6 February 2017

Accepted 21 February 2017

Available online 6 March 2017

\section{Keywords:}

Fungi

Biogeography

Temperate grassland

Regional scale

Illumina sequencing

\begin{abstract}
A B S T R A C T
Fungi play an important regulating role in terrestrial ecosystem functioning. However, their biogeographic distribution patterns along combined gradients of plant communities and environmental variables across regional spatial scales remain poorly understood. This knowledge gap is particularly pronounced in arid and semi-arid grassland ecosystems, which occupy one third of the terrestrial surface of China. Here, a regional-scale field investigation was conducted to collect soil samples from 290 plots at 52 sites along a $4000 \mathrm{~km}$ transect in temperate grasslands of northern China to assess the distribution patterns of fungal communities. The high-throughput Illumina sequencing revealed that soil fungal communities were dominated by Ascomycota, Basidiomycota and Zygomycota across the temperate grasslands. Fungal richness increased with plant species richness and mean annual precipitation (MAP). Bray-Cutis dissimilarities in soil fungal community composition between sites were significantly correlated with plant community composition, geographical distance, and abiotic factors including MAP, mean annual temperature, soil $\mathrm{pH}$, and soil organic carbon. Variation partitioning analysis revealed that variation in fungal community composition was mainly explained by plant community composition, followed by geographical distance and abiotic factors. Structural equation models further highlighted the significant role of plant species richness in determining soil fungal richness. Taken together, these results suggest that the regional-scale distribution pattern of soil fungal communities is predominantly mediated by plant community composition, and also by abiotic factors and geographical distance in arid and semi-arid temperate grasslands.
\end{abstract}

๑) 2017 Elsevier Ltd. All rights reserved.

\section{Introduction}

Fungi represent one of the most diverse groups of living organisms, and play an essential role in terrestrial ecosystem functioning as plant decomposers (e.g. wood-decaying Basidiomycetes), pathogens and symbionts (e.g. forming mycorrhizal associations) (Zeilinger et al., 2015). There is also evidence that subsets of soil

\footnotetext{
* Corresponding author. Research Center for Eco-Environmental Sciences, Chinese Academy of Sciences, 18 Shuangqinglu, Haidian District, Beijing, 100085, China.

E-mail address: bdchen@rcees.ac.cn (B.-D. Chen).

1 These authors contributed equally to this work and are joint first authors.
}

fungi such as arbuscular mycorrhizal fungi have the potential to influence plant productivity and diversity by increasing available nutrient pools, especially in nutrient-poor ecosystems where plant symbionts are largely responsible for the acquisition of limiting nutrients (Van der Heijden et al., 1998, 2008; Klironomos et al., 2011; Bardgett and van der Putten, 2014). Therefore, studying biogeographic patterns of soil fungal communities could provide valuable clues for understanding biogeochemical nutrient cycles, ecosystem processes and services.

Understanding which factors drive observed biogeographical patterns of soil microbial communities is a key objective in microbial ecology (Martiny et al., 2006). Despite their ubiquity in terrestrial ecosystems and importance in ecological functioning, 
the diversity and distribution patterns of soil microbes at regional scales are far less understood than the respective distribution patterns of above-ground macro-organisms such as plants and animals (Martiny et al., 2006). Mounting evidence suggests that soil $\mathrm{pH}$ represents a key regulator in shaping the distribution of soil bacterial communities at regional scales (Fierer and Jackson, 2006; Lauber et al., 2009). However, compared with bacteria, little is known about the regional-scale biogeographic distribution patterns of soil fungal communities. Fungi depend more on plant products (Millard and Singh, 2010) and their biotrophic interactions with plants because a large proportion of them act as endophytes, mutualists or pathogens (Wardle, 2006; Gao et al., 2013). Therefore, it is assumed that there would be a strong coupling of plant-fungal distribution patterns at regional scales. Although some site-specific studies reported positive relationships between plant and fungal diversity (Van der Heijden et al., 1998; Hiiesalu et al., 2014), comprehensive empirical evidence from regional scales remain scarce. Furthermore, the range of environmental parameters that are considered in such regional studies is usually limited due to logistic constraints and to the best of our knowledge there have been no field studies that simultaneously considered the relative role of multiple spatial factors, abiotic factors and plant community composition in shaping soil fungal communities at regional scales. This represents a major knowledge gap in our understanding of fungal biogeography.

Biogeographical studies focusing on soil fungal communities have been conducted in European grasslands (Pellissier et al., 2014; Geremia et al., 2016), arctic tundra (Timling et al., 2014) and various forest ecosystems including temperate forests, tropical forests and boreal forests (Wubet et al., 2012; Peay et al., 2013; Taylor et al., 2014). With a focus on temperate grasslands and drylands there have been two recent surveys with a global scope which exemplified how fungal communities are influenced by coarse environmental heterogeneity (Maestre et al., 2015; Prober et al., 2015). These two comprehensive studies have revealed that aridity and plant beta diversity are important predictors of fungal community compositions (beta diversity). Coarse environmental gradients however may lack the resolution required to disentangle confounding effects of different predictors. For instance, latitudinal gradients may be confounded with temperature changes or vice versa. The logistics of the two earlier mentioned global studies may have prevented a sufficiently intense sampling to fully appreciate the importance of individual environmental drivers. Moreover, we can expect that some drivers that are important at a global scale (such as dispersal) will be less important at regional scale and vice versa (e.g. altitude). Therefore, a regional study on Asian grassland ecosystems could represent an excellent compromise between the abovementioned global studies and the existing smaller scale studies.

The temperate grasslands in northern China represent typical arid and semi-arid ecosystems, occupying one third of the land surface of China. The habitats in this region have been described to be exceptionally fragile and are predicted to suffer from a projected higher frequency of extreme climatic phenomena such as increased drought and precipitation (Ni and Zhang, 2000; Wang et al., 2015). It was suggested that the total area of arid and semi-arid ecosystems will expand as a result of global warming (Dai, 2013) and simultaneously precipitation events will become less regular (Easterling et al., 2000). These changes could induce substantial changes on the growth rates and community assembly structures of soil fungi (Maestre et al., 2015; Vargas-Gastélum et al., 2015). Therefore, it is highly desirable to improve our understanding of the ecology and functioning of soil fungi in arid and semi-arid ecosystems.

Here, we present a regional-scale field study spanning 52 temperate grassland sites in northern China to examine the distribution patterns and driving factors of soil fungal communities using high-throughput sequencing technologies. The studied region is characterized by a decreasing precipitation gradient from the east to the west, and encompasses a wide variety of climatic, edaphic and vegetation conditions (Chen et al., 2014a; Wang et al., 2015). We tested the following hypotheses: (1) plant species richness and community composition are positively related to soil fungal richness and community composition in temperate grasslands in agreement with earlier studies that have demonstrated that plant community structure represents a major environmental filter for fungi (Prober et al., 2015); and (2) after accounting for plant dependencies, climatic predictors, and MAP in particular, would explain a considerable proportion of cross-community variability as has been shown in other regional and global studies (Pellissier et al., 2014; Tedersoo et al., 2014).

\section{Materials and methods}

\subsection{Study sites, field investigation and soil sampling}

The study sites span a latitudinal gradient of $36.36^{\circ} \mathrm{N}-48.54^{\circ} \mathrm{N}$ and a longitudinal gradient of $83.84^{\circ} \mathrm{E}-125.00^{\circ} \mathrm{E}$, and cover seven provinces in North China including Heilongjiang, Inner Mongolia, Hebei, Shanxi, Gansu, Qinghai, and Xinjiang (Fig. 1; Table S1). Four major grassland types can be identified in this region including meadow steppe, typical steppe, desert steppe and desert. The mean annual precipitation (MAP) ranges from $75 \mathrm{~mm}$ to $557 \mathrm{~mm}$, and the mean annual temperature (MAT) from $-1.5^{\circ} \mathrm{C}$ to $9.6^{\circ} \mathrm{C}$.

A field sampling campaign was conducted during the growing season from July to August in 2012. A total of 312 soil samples were collected from 52 sites along a $4000 \mathrm{~km}$ transect, which covered all the major climate zones and grassland types, and were at least $1 \mathrm{~km}$ away from main roads to avoid influences of anthropogenic activities (Table S1). At each site, spatial geographic coordinates (longitude and latitude) and elevation were recorded using a GPS device (eTrex Venture, Garmin, USA). All the sites were surveyed using a standardized sampling protocol. Briefly, six random $1 \mathrm{~m} \times 1 \mathrm{~m}$ plots were arranged within an area of $10 \mathrm{~m} \times 10 \mathrm{~m}$ for each site. The plot-scale measures of plant species composition included the species richness (SR), Shannon-Wiener diversity, and the number of each plant species within the $1 \mathrm{~m}^{2}$ plot. We used the Angiosperm Phylogeny Group (APG) III system (Chase and Reveal, 2009 ) to identify plants taxonomically. Five soil cores $(3 \mathrm{~cm}$ in diameter and $10 \mathrm{~cm}$ in depth) were collected randomly from each plot, stored in polyethylene bags and transported on ice to the laboratory. After thorough homogenization and removal of roots and stones, the composite soils were sieved through a 2-mm mesh and divided into two portions. One portion was stored at $4{ }^{\circ} \mathrm{C}$ for characterization of soil physical and chemical properties, and another portion was stored at $-80{ }^{\circ} \mathrm{C}$ prior to DNA extraction and molecular analysis.

\subsection{Soil physicochemical characterization and climate data collection}

Soil moisture content was measured gravimetrically by ovendrying the fresh soil samples at $105{ }^{\circ} \mathrm{C}$ for $24 \mathrm{~h}$. Soil ammonium and nitrate were extracted with $2 \mathrm{M} \mathrm{KCl}$ (a soil to water ratio of 1:5) and measured using a continuous flow analyzer (SAN++, Skakar, Breda, Holland). Soil pH was determined in a soil suspension with a soil: water ratio of 1: $2.5(\mathrm{w} / \mathrm{v})$ using a Delta $320 \mathrm{pH}$-meter (Mettler-Toledo Instruments Co., Shanghai, China). Total carbon (TC) and total nitrogen (TN) were determined on an element analyzer (Vario EL Ш, Elementar, Germany). Soil organic carbon (SOC) was measured using a $\mathrm{K}_{2} \mathrm{Cr}_{2} \mathrm{O}_{7}$ oxidation method as described in 


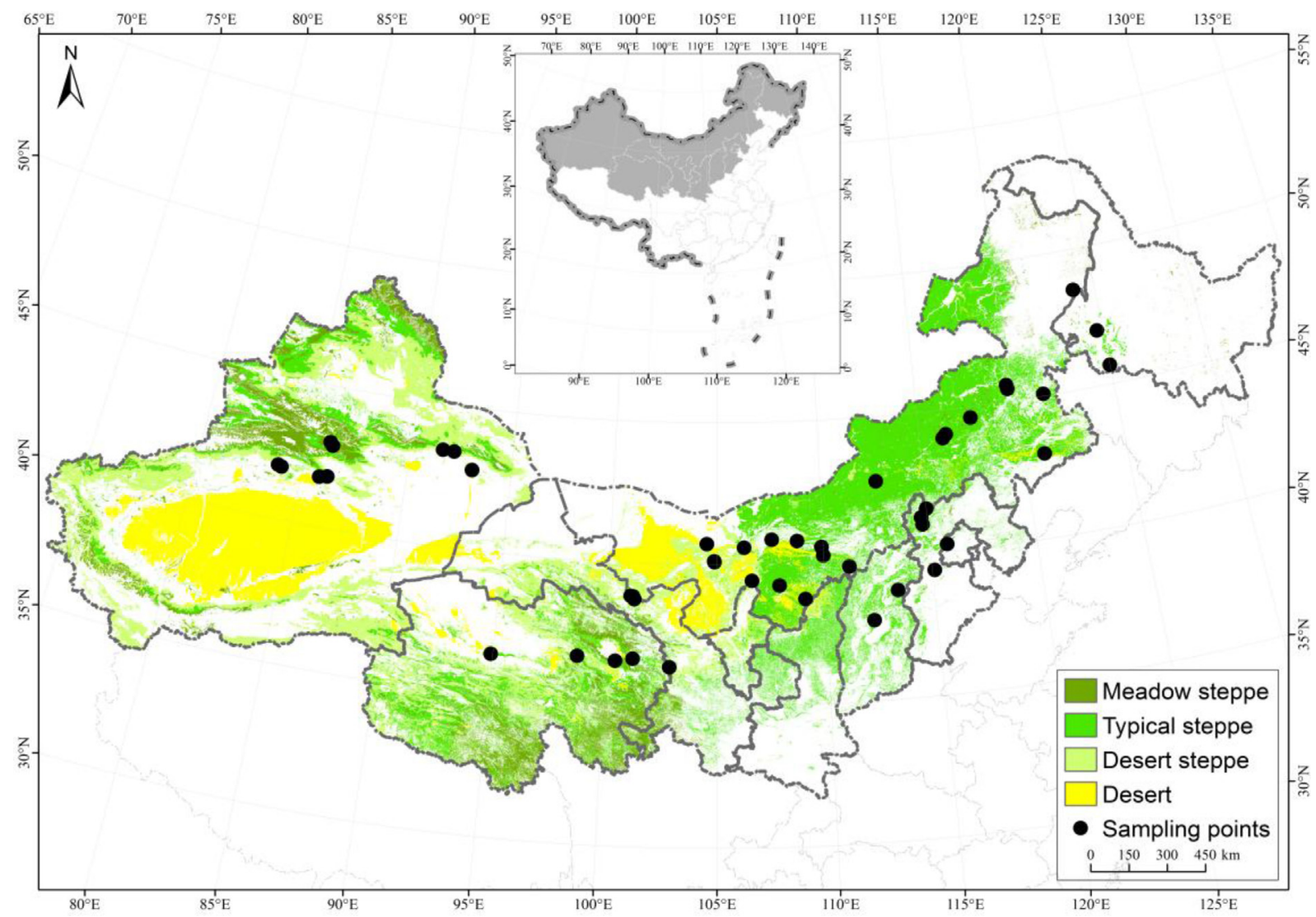

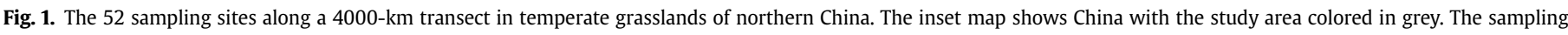

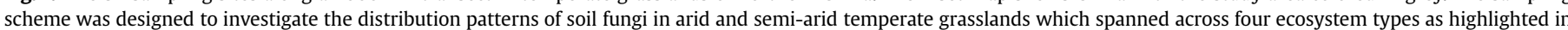
the legend.

Walkley (1947). Soil texture was determined on a particle size analyzer after removal of organic matter and calcium carbonates using $\mathrm{H}_{2} \mathrm{O}_{2}$. Soil available phosphorus (AP) was extracted with $0.5 \mathrm{M} \mathrm{NaHCO}_{3}$ and measured using a colorimetric method (Murphy and Riley, 1962). Soil carbon: nitrogen (C: N) ratio was calculated based on SOC and TN. The data of MAT and MAP for each site were obtained from the China Meteorological Data Sharing Service System (http://cdc.cma.gov.cn/).

\subsection{DNA extraction, PCR amplification, and illumina-based sequencing}

We used $0.25 \mathrm{~g}$ of each soil sample to extract DNA using the PowerSoil ${ }^{\circledR}$ DNA Isolation Kit (MO BIO Laboratories, San Diego CA) according to the manufacturer's instructions. The quality and concentration of the extracted DNA were quantified using a NanoDropND-2000c UV-Vis Spectrophotometer (NanoDrop Technologies, Wilmington, DE, USA). The primer set ITS1F (Gardes and Bruns, 1993) and ITS2 (White et al., 1990) was used to amplify the fungal internal transcribed spacer (ITS) region. Although the ITS1F primer could likely result in an undercounted estimate of Glomeromycota (Porras-Alfaro et al., 2007; Hudson et al., 2015), the ribosomal ITS region offers several advantages over other molecular markers in terms of high information content and ease of amplification (Schoch et al., 2012). The reverse primer contained variable length error-correcting barcodes (10-12 bp) unique to each sample to permit sequencing on the Illumina Miseq platform. PCR amplification was performed for each soil DNA extract in triplicate and combined into a single composite sample. The $25 \mu$ PCR reaction mixture contained $1 \mu \mathrm{l}$ of ten-fold diluted DNA template (1-10 ng), $0.5 \mu \mathrm{l}$ of each primer $(10 \mu \mathrm{M}), 0.5 \mu \mathrm{l}$ of Taq DNA polymerase (2.5 U $\mu \mathrm{l}^{-1}$; TaKaRa Biotechnology Co. Ltd). The thermal-cycling conditions were as follows: $94^{\circ} \mathrm{C}$ for $3 \mathrm{~min}$; 35 cycles of $94{ }^{\circ} \mathrm{C}$ for $45 \mathrm{~s}$, $50{ }^{\circ} \mathrm{C}$ for $60 \mathrm{~s}$, and $72{ }^{\circ} \mathrm{C}$ for $60 \mathrm{~s}$; and followed by $72{ }^{\circ} \mathrm{C}$ for $10 \mathrm{~min}$. PCR products were gel-purified using the QIAEX Gel Extraction Kit (Qiagen, Valencia, CA, USA), and quantified using a Quant-iT dsDNA HS Assay Kit (Invitrogen, Carlsbad, CA, USA). The resultant PCR products were combined at equimolar concentrations before being sequenced on an Illumina Miseq sequencer at the Chinese National Human Genome Center in Shanghai.

\subsection{Bioinformatic analyses}

The obtained raw ITS sequence data were processed using the Quantitative Insights Into Microbial Ecology (QIIME) pipeline (Caporaso et al., 2010). Briefly, sequencing reads with an average quality value $<30$, with ambiguous nucleotides in barcodes and shorter than 200 bp were removed to improve sequence quality. The de novo chimera detection was performed using USEARCH (Edgar, 2010). The ITS1 subregion was extracted from each sequence using Fungal ITS Extractor 1.1 (Henrik et al., 2011). All sequences were clustered into operational taxonomic units (OTUs) at a $97 \%$ identity threshold using UCLUST (Edgar, 2010). Taxonomy was assigned to each sequence through BLASTing against the UNITE database (Abarenkov et al., 2010). The OTUs containing less than five reads were eliminated to reduce the risk of artificially inflating richness due to sequencing errors (Caporaso et al., 2011). The highquality fungal sequences ranged from 4066 to 55,542 per sample, 
with an average of 14,975 reads per sample. To correct for the sampling effort, we used a randomly selected subset of 4000 fungal sequences per sample for the downstream analysis. Alpha diversity of soil fungi was estimated by calculating the OTU richness and Shannon-Wiener diversity indices at $97 \%$ sequence identity. To estimate the similarity in soil fungal communities, Bray-Curtis dissimilarity matrices were generated for the beta diversity of fungal communities.

The DNA sequences in this study have been deposited in SRA of NCBI database under accession number SRR5188412.

\subsection{Statistical analyses}

One-way analysis of variance (ANOVA) was performed to assess the differences in the fungal richness, Shannon-Wiener index and the relative abundance of the major fungal phyla among the four different ecosystems. Data that were not normally distributed were $\log (\chi+1)$-transformed. The relationships between OTU richness or plant species richness with biotic and abiotic factors were tested with Pearson correlation. All these analyses were performed using the software SPSS 19.0 (IBM Corporation, Armonk, NY).

Community tables describing the relative abundance of fungal taxa and plant species composition were used as primary data to calculate Bray Curtis site distance tables for fungi and plants, respectively. These distance tables were subsequently standardized in the range between 0 and 1 and were used as a means describing geographic distance between sites (Byrnes et al., 2014). The relationships between fungal community and plant community, geographic distance and abiotic variables were assessed using Mantel test with the "ecodist" and "vegan" packages in R (Goslee and Urban, 2007; R Development Core Team., 2013). To control for the co-varying effects of factors, partial Mantel tests were carried out with each of the significant independent variables according to the results of Mantel test.

Venn diagrams for graphical descriptions of unique and shared fungal OTUs between different ecosystems were calculated using the "VennDiagram" package in R. Principal coordinates analysis (PCoA) of the fungal community composition based on the BrayCurtis distance was conducted using the CANOCO 5.0 software (Microcomputer Power, Ithaca, NY, USA). To test whether there were significant difference in fungal community composition among different ecosystems, Adonis analyses were carried out with the "vegan" package in R. To assess the relative importance of each driver, we implemented a redundancy analysis (RDA) approach. As predictors we used the following variables: plant community, spatial characteristics and abiotic factors (climatic and edaphic variables). The plant community composition was captured by the first 30 of the 249 axes derived from a PCoA based on the BrayCurtis dissimilarity matrix, which represented more than $70 \%$ of the total variation of the plant community composition. The principal coordinates of neighbor matrices (PCNM) were calculated to model the spatial structure of the 52 sites (Dray et al., 2006). All these variation partitioning analyses were performed in $\mathrm{R}$ using the "vegan", "ape", and "packfor" packages.

A structural equation model (SEM) was applied to test for the direct and indirect effects of climate, spatial factors, soil fertility, soil texture and plant diversity on the fungal richness according to hypothesized causal relationships, using the Amos 17.0 software (Smallwaters Corporation, Chicago, IL, USA). We chose MAP, SOC and silt content as independent variables as these three factors showed the strongest correlations with fungal species richness among climate, soil nutrient and soil texture variables, respectively. Plant species richness was used as a separate indicator owing to its proposed close relationship with fungal richness (Wardle, 2006). Model fits were determined according to a non-significant $\chi^{2}$ test
$(P>0.05)$, low Akaike value (AIC), high goodness of fit index (GFI; > 0.90 ), and low root square mean error of approximation (RMSEA; < 0.05) (Hooper et al., 2008). Standardized total effects of spatial factors, MAP, silt content, SOC, plant species richness on fungal richness were also calculated for SEM.

\section{Results}

3.1. An overview of the illumina sequencing results for the soil fungal community

A total of 22 samples from 14 sites were excluded due to their low sequence numbers, resulting in 290 samples for the downstream analyses (Table S2). The high-throughput Illumina sequencing yielded a total of 4,959,240 sequences for the 290 soil samples, and 4,342,795 sequences ( $87.6 \%$ of all reads) were identified as fungal sequences (Table S2). After randomly subsampling 4000 fungal sequences from each sample, the total number of fungal sequences used for the downstream analysis was $1,160,000$ (Table S3). The dominant fungal phyla across all samples were Ascomycota (68.9\% of the total fungal sequences), Basidiomycota (10.8\%) and Zygomycota (7.0\%) (Fig. 2a). Chytridiomycota and Glomeromycota were minor phyla, accounting for $0.9 \%$ and $0.4 \%$ of the total fungal sequences, respectively (Fig. 2a). The classified fungal sequences were binned into 11,542 OTUs at 97\% sequence identity (Fig. 2b). The Ascomycota phylum harbored the highest OTU richness (7446 OTUs), following by Basidiomycota (2118 OTUs), unidentified fungi (936 OTUs), Zygomycota (553 OTUs), Glomeromycota (339 OTUs), and Chytridiomycota (150 OTUs).

\subsection{Fungal diversity and community compositions across the four grassland ecosystems}

Fungal richness was highest in typical steppe, followed by meadow steppe and desert steppe, with the lowest value recorded in desert $(P<0.05$; Fig. 3a). Shannon-Wiener index of fungi in desert was significantly lower than those in desert steppe, typical steppe and meadow steppe $(P<0.05$; Fig. $3 b)$. Among the four ecosystems, Ascomycota was the most dominant phylum (Fig. 3c), with the highest relative abundance found in desert and desert steppe, and the lowest in meadow steppe (Fig. S1a). The relative abundance of Basidiomycota did not significantly change across the four ecosystems (Fig. S1b). The relative abundance of Chytridiomycota was highest in meadow steppe and lowest in desert and typical steppe (Fig. S1c). By contrast, the relative abundances of Glomeromycota, Zygomycota and unidentified fungi were highest in meadow steppe or typical steppe (Fig. S1d, e, f).

The number of detected OTUs also varied across the four grassland ecosystems (Fig. 3d). For example, a total of 5026 OTUs were detected in the desert, 3573 in the desert steppe, 7771 in the typical steppe and 6197 in the meadow steppe (Fig. 3d). The unique OTUs detected in a single ecosystem was 1044 for desert, 463 for desert steppe, 2531 for typical steppe and 1427 for meadow steppe (Fig. 3d). When the four ecosystems were compared, we found that they shared 1672 OTUs (Fig. 3d).

\subsection{Relationships between fungal alpha diversity and climatic, edaphic and biotic factors}

Alpha diversity of fungi, measured as fungal OTU richness at $97 \%$ sequence identity, showed obvious variation across the temperate grasslands. Pearson's correlation analysis revealed that among all the biotic and abiotic factors, fungal richness had the strongest (positive) correlation with SR $(P<0.01$; Fig. 4a), and followed by MAP $(P<0.05$; Table 1$)$. Significant correlations were also found 
(a) Total relative abundance

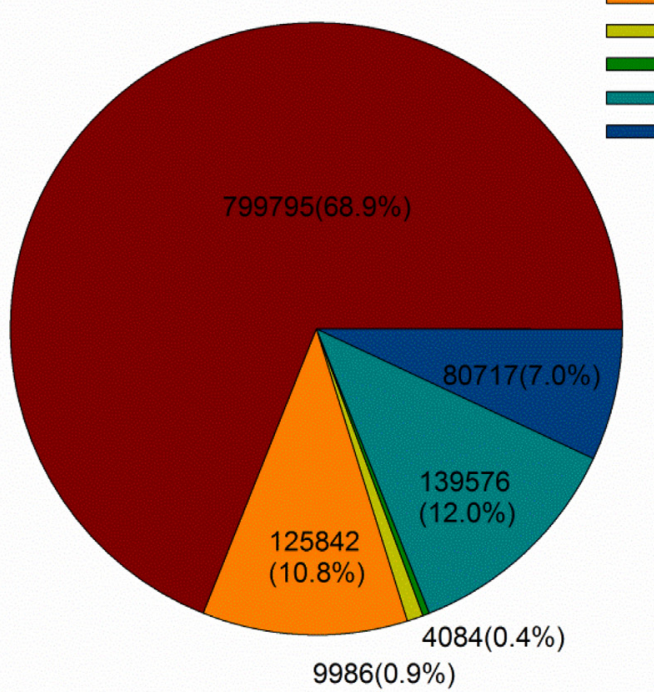

(b) OTU numbers

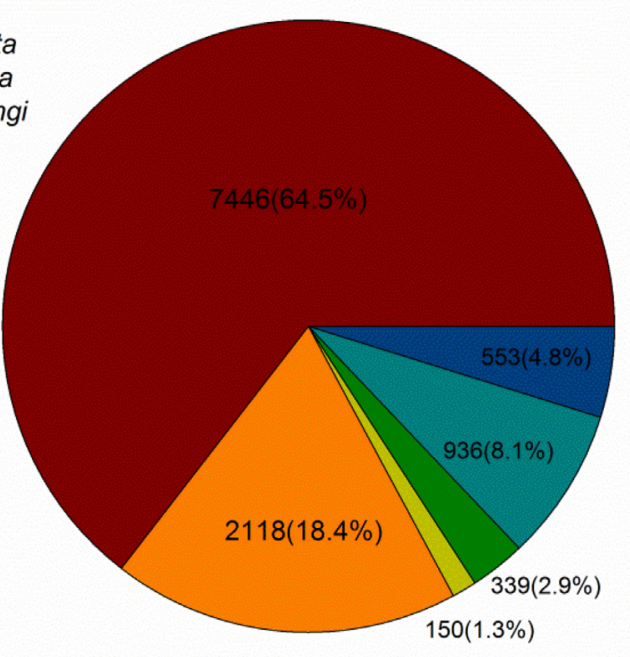

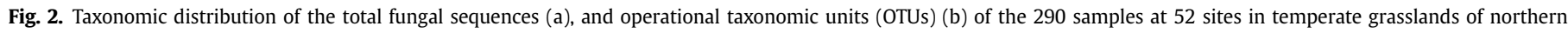
China.

between fungal richness and other environmental variables such as MAT, silt content, SOC, TN, ammonia concentration and nitrate concentration $(P<0.05$; Table 1$)$.

\subsection{Correlations of fungal beta diversity with plant community composition, geographical distance and abiotic factors}

The relationships between fungal beta diversity with plant community composition, geographical distance and abiotic factors were assessed with Mantel and partial Mantel test. Among all the explanatory variables, geographical distance had the strongest correlation with fungal community composition $(P<0.001$; Table 2; Fig. S2). There were also significant correlations of fungal community composition with plant community compositions and abiotic factors such as MAP, MAT, $\mathrm{pH}$ and SOC $(P<0.01$; Table 2; Fig. 4b).

The PCoA showed significant differences in soil fungal communities between the four ecosystem types (Fig. 5a; Table S4). A variance partitioning analysis was conducted to assess the relative contributions of plant community composition, abiotic factors and
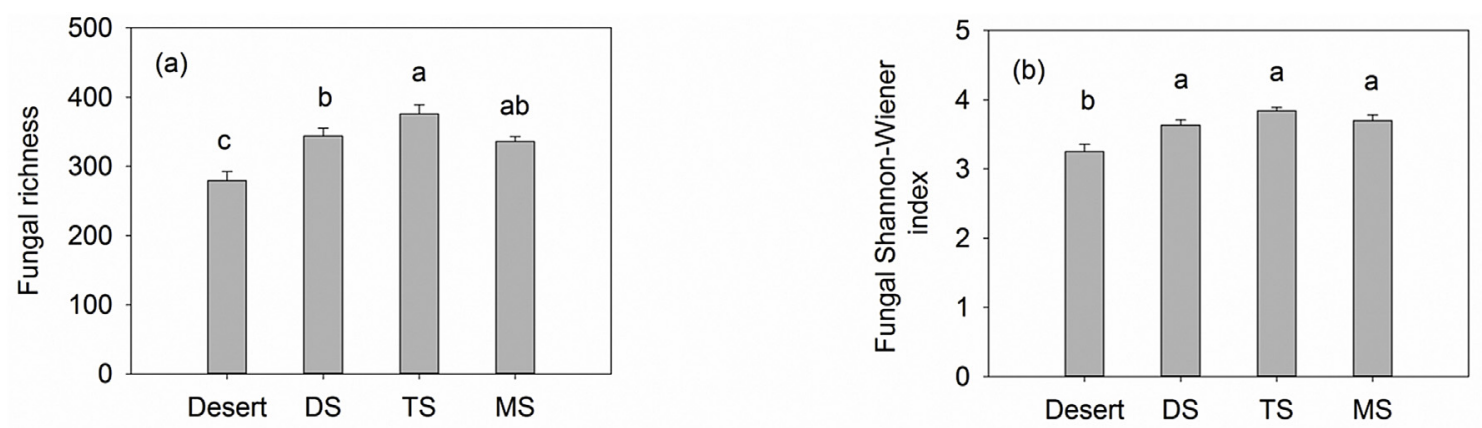

(c)

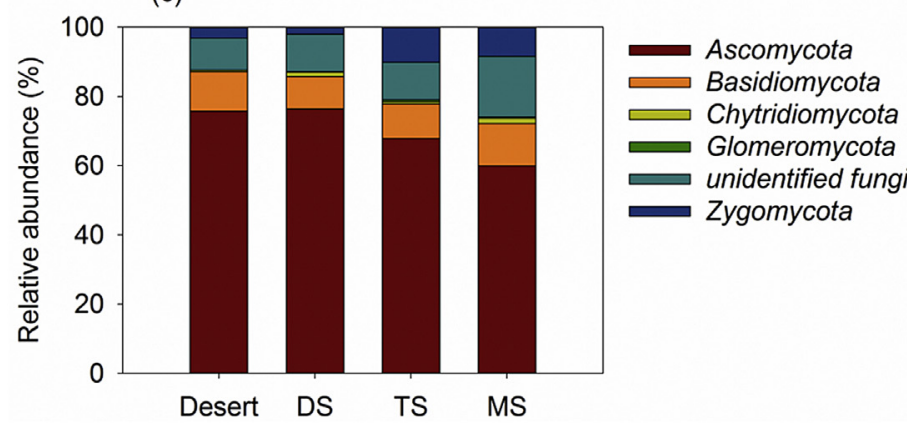

(d)

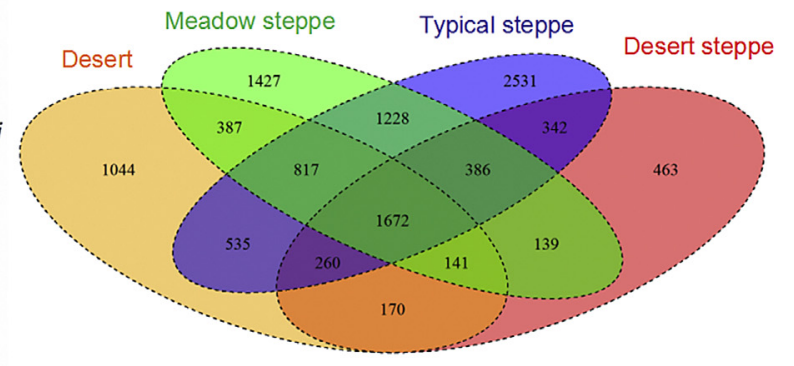

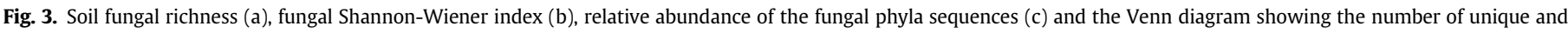
overlapping OTUs (d) in the four grassland ecosystems of northern China. DS: Desert steppe; MS: meadow steppe; TS: typical steppe. 

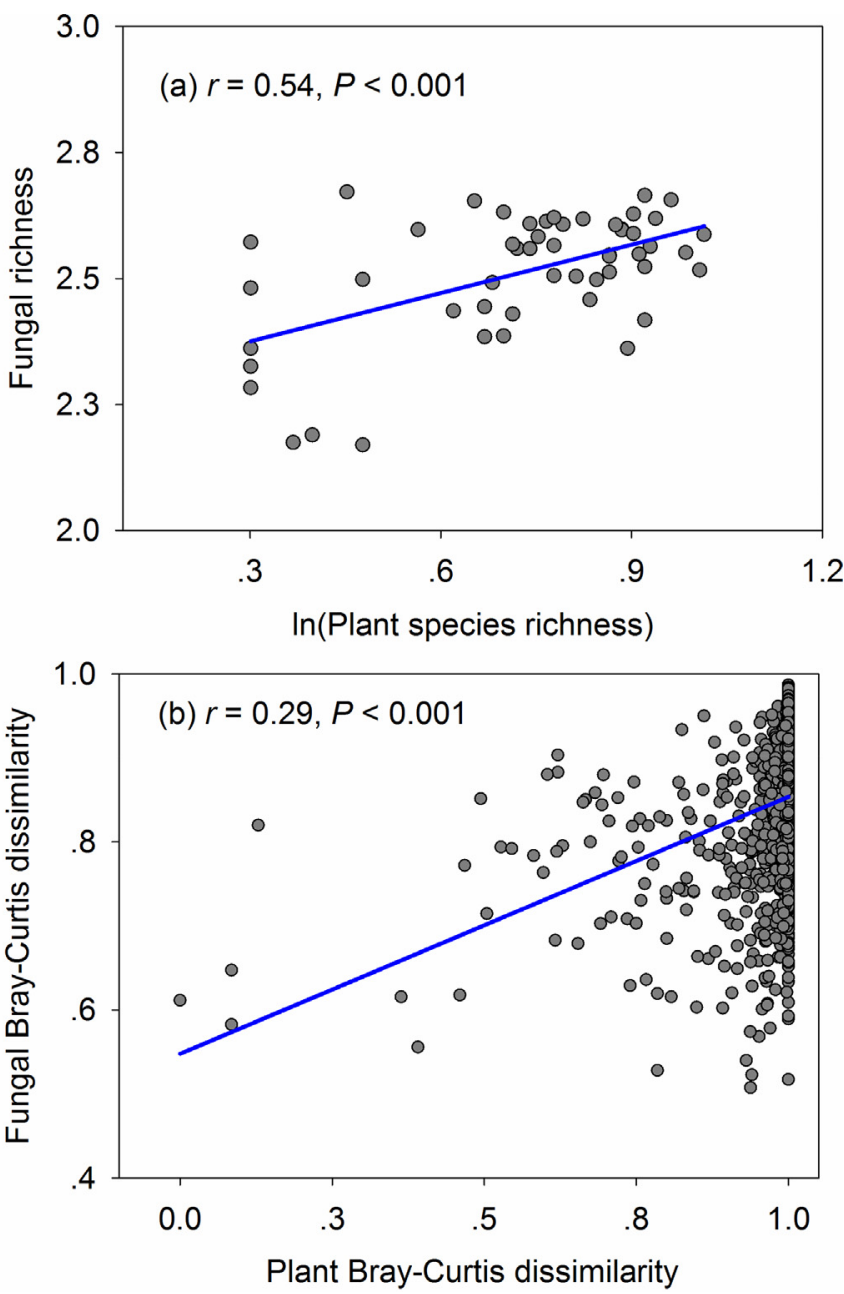

Fig. 4. The linear relationships between fungal richness and plant species richness (a), and between fungal communities and plant communities (b), measured at plot scale and pooled at site level across temperate grasslands of northern China.

spatial distance to soil fungal communities. The combination of these variables explained $23.8 \%$ of the observed variation in soil fungal community composition (Fig. 5b). Plant community composition explained the largest fraction of the variation (17.1\%), with a pure effect of $9.0 \%$. Abiotic factors (including climate and edaphic factors) and spatial factors (as represented by the PCNM variables) explained $10.4 \%$ and $9.8 \%$ of the variation, respectively.

SEM was used to assess the direct and indirect effects of explanatory variables on fungal richness (Fig. 6). The fitted models explained $39 \%$ of the variance in fungal richness (Fig. 6a). Silt content and SR were identified as significant drivers of fungal richness. Standardized total effects derived from the SEM revealed that fungal richness was mainly driven by spatial factors, followed by silt content, MAP, SR and SOC (Fig. 6b).

\section{Discussion}

\subsection{Soil fungal alpha and beta diversity across the four temperate grassland ecosystems}

We observed higher fungal richness and Shannon-Wiener index in grasslands compared to deserts. This might have resulted from grasslands hosting more diverse plant communities that represented the most influential predictor of fungal community
Table 1

Relationships of fungal and plant richness with environmental variables, measured at the plot scale and pooled at the site level.

\begin{tabular}{|c|c|c|c|c|}
\hline \multirow[t]{2}{*}{ Explanatory } & \multicolumn{2}{|l|}{ Fungi } & \multicolumn{2}{|l|}{ Plant } \\
\hline & $r$ & $P$ & $r$ & $P$ \\
\hline $\mathrm{MAP}(\mathrm{mm})$ & 0.495 & 0.000 & 0.653 & 0.001 \\
\hline $\operatorname{MAT}\left({ }^{\circ} \mathrm{C}\right)$ & -0.327 & 0.018 & -0.290 & 0.037 \\
\hline $\mathrm{pH}$ & -0.264 & 0.058 & -0.101 & 0.476 \\
\hline $\mathrm{AP}\left(\mathrm{mg} \mathrm{kg}^{-1}\right)$ & -0.036 & 0.802 & -0.016 & 0.908 \\
\hline Clay content (\%) & -0.251 & 0.072 & -0.033 & 0.816 \\
\hline Silt content (\%) & -0.299 & 0.031 & -0.094 & 0.509 \\
\hline Sand content (\%) & 0.264 & 0.058 & -0.015 & 0.917 \\
\hline SOC (\%) & 0.329 & 0.017 & 0.335 & 0.015 \\
\hline $\mathrm{TN}(\%)$ & 0.297 & 0.032 & 0.305 & 0.028 \\
\hline $\begin{array}{l}\text { Nitrate concentration } \\
\left(\mathrm{mg} \mathrm{kg}^{-1}\right)\end{array}$ & -0.314 & 0.023 & -0.222 & 0.114 \\
\hline $\begin{array}{l}\text { Ammonium concentration } \\
\left(\mathrm{mg} \mathrm{kg}^{-1}\right)\end{array}$ & 0.293 & 0.035 & 0.267 & 0.056 \\
\hline $\mathrm{C}: \mathrm{N}$ ratio & 0.048 & 0.737 & 0.136 & 0.336 \\
\hline
\end{tabular}

Notes: MAP, mean manual precipitation; MAT, mean manual temperature; AP, available phosphorus; SOC, soil organic carbon; TN: total nitrogen; C:N ratio: soil organic carbon: total nitrogen. Values in bold indicate significant correlations $(P<0.05)$.

structure. Alternatively, there were systematic differences in MAT, MAP (data not shown) between the two habitats that could also account for the differences in fungal community structure either through direct effects or through their influence on plant richness and edaphic conditions. Our results indicated that Ascomycota (comprising $64.5 \%$ of the fungal OTUs and $68.9 \%$ of fungal sequences) are more dominant than Basidiomycota, Chytridiomycota, Glomeromycota and Zygomycota in temperate grasslands of northern China (Fig. 2). The dominance of Ascomycota may reflect a unique distribution pattern of fungi in arid and semiarid ecosystems. For instance, Ascomycota were found to dominate the fungal phylum in semi-arid grasslands (Porras-Alfaro et al., 2011; VargasGastélum et al., 2015), global drylands (Maestre et al., 2015) and temperate grasslands (Prober et al., 2015). However, this study differs from a recent global survey of soil fungi reporting a dominance of Basidiomycota in terrestrial ecosystems (Tedersoo et al., 2014). The differences between Tedersoo et al. (2014) and our study could be attributed to the fact that the representation of

Table 2

Correlations of fungal and plant beta diversity (plot-scale dissimilarities across sites, and pooled at the site level) with geographical distance and environment factors as revealed by Mantel test.

\begin{tabular}{|c|c|c|c|c|}
\hline \multirow[t]{2}{*}{ Explanatory } & \multicolumn{2}{|l|}{ Fungi } & \multicolumn{2}{|l|}{ Plant } \\
\hline & $r_{\mathrm{M}}$ & $P$ & $r_{M}$ & $P$ \\
\hline Geographical distance (km) & 0.338 & 0.001 & 0.242 & 0.001 \\
\hline $\mathrm{MAP}(\mathrm{mm})$ & 0.307 & 0.001 & 0.202 & 0.001 \\
\hline $\operatorname{MAT}\left({ }^{\circ} \mathrm{C}\right)$ & 0.199 & 0.017 & 0.107 & 0.004 \\
\hline $\mathrm{pH}$ & 0.220 & 0.006 & 0.045 & 0.276 \\
\hline $\mathrm{AP}\left(\mathrm{mg} \mathrm{kg}^{-1}\right)$ & 0.103 & 0.093 & 0.013 & 0.682 \\
\hline Clay content (\%) & 0.090 & 0.259 & 0.081 & 0.026 \\
\hline Silt content (\%) & -0.041 & 0.555 & 0.092 & 0.011 \\
\hline Sand content (\%) & 0.144 & 0.063 & 0.072 & 0.043 \\
\hline SOC (\%) & 0.175 & 0.022 & 0.091 & 0.019 \\
\hline $\mathrm{TN}(\%)$ & 0.153 & 0.077 & 0.080 & 0.035 \\
\hline $\begin{array}{l}\text { Nitrate concentration } \\
\left(\mathrm{mg} \mathrm{kg}^{-1}\right)\end{array}$ & 0.082 & 0.142 & 0.079 & 0.016 \\
\hline $\begin{array}{l}\text { Ammonium concentration } \\
\left(\mathrm{mg} \mathrm{kg}^{-1}\right)\end{array}$ & 0.120 & 0.184 & 0.067 & 0.083 \\
\hline $\mathrm{C}: \mathrm{N}$ ratio & -0.070 & 0.371 & 0.074 & 0.046 \\
\hline
\end{tabular}

Notes: MAP, mean manual precipitation; MAT, mean manual temperature; AP, available phosphorus; SOC, soil organic carbon; TN: total nitrogen; $\mathrm{C}$ : $\mathrm{N}$ ratio: soil organic carbon: total nitrogen. Values in bold indicate significant correlations $(P<0.05)$. 

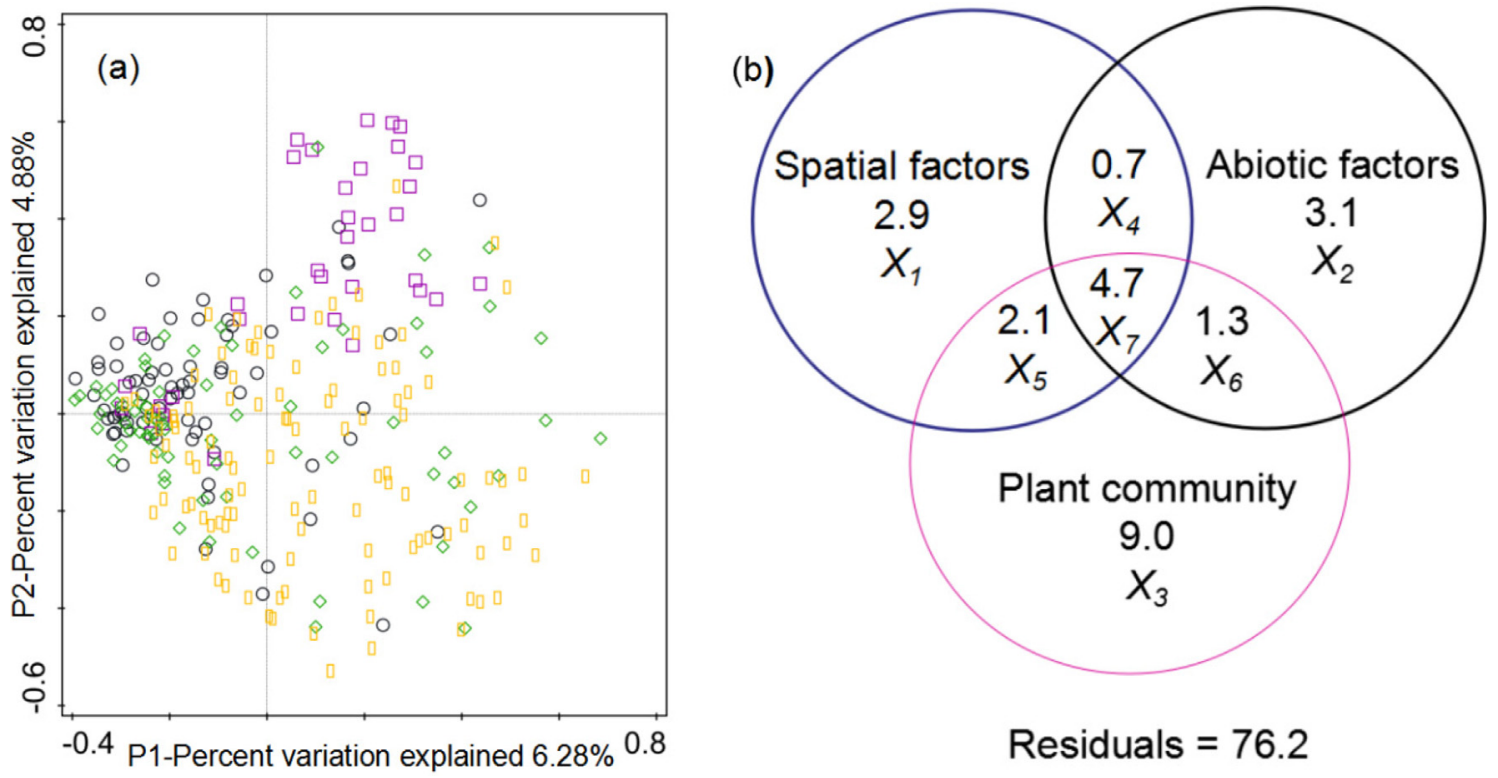

Residuals $=76.2$

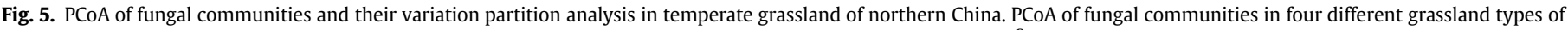

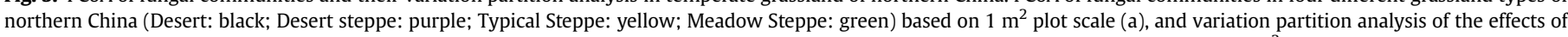

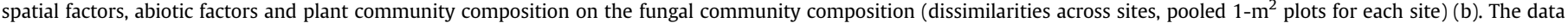
present percentage (\%) of variation explained by the factors.

semiarid grasslands was considerably lower in Tedersoo et al. (2014). Grasslands are unsuitable habitats for ectomycorrhizal fungi, and thus having included more grasslands implied a lower diversity of Basidiomycetes to be expected in our study.

We also found clear differences in soil fungal communities among the four grassland ecosystems in northern China mostly with regards to the relative abundance of Ascomycota. This result was in line with the observations that fungi are often predominated by oligotrophic Ascomycetes in environments with scarce resource availability in terms of carbon or nutrients as well as drought stress (Clemmensen et al., 2015; Sterkenburg et al., 2015). Our results indicated that Ascomycetes may have the ability to tolerate stressful conditions, and achieve a more resource use efficiency in harsh environments. By contrast, we found that the relative abundance of Basidiomycota (comprising 10-13\% of the obtained sequences) was relatively steady across the four different ecosystems. Many ectomycorrhizal fungi and saprotrophic fungi in forest ecosystems are Basidiomycetes (Sterkenburg et al., 2015), which however may respond in contrasting ways to habitat heterogeneity (Tedersoo and Bahram, 2016). For example, the relative dominance of EcM fungi and saprotrophs has been suggested to change with plant allocation of photosynthetic products between roots and leaves in boreal forests or with soil fertility (Högberg et al., 2003). Nevertheless, there is less litter and humus in temperate grasslands

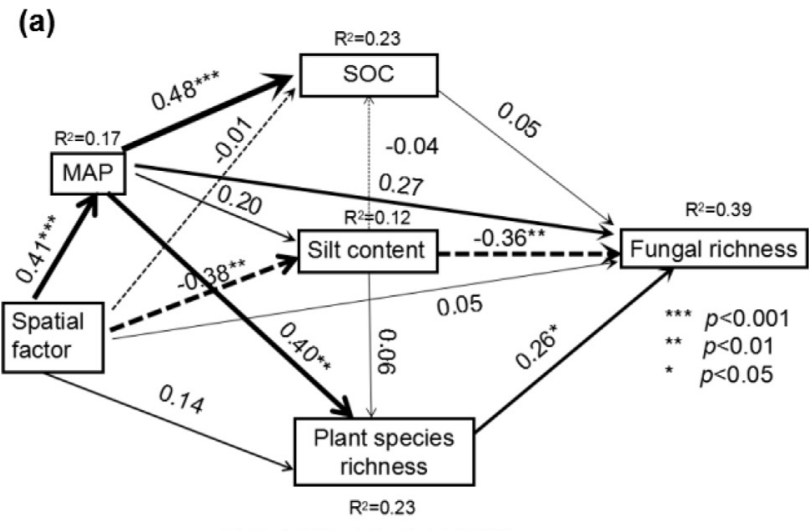

(b)

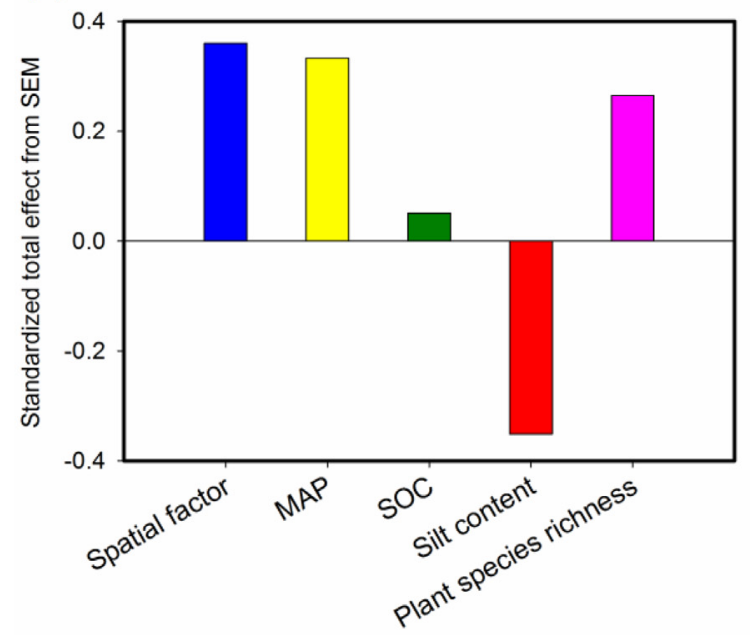

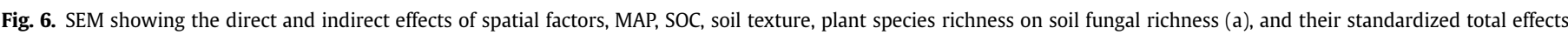

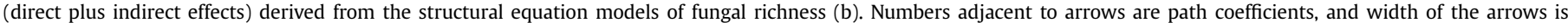

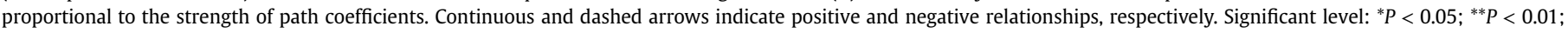
*** $P<0.001$ 
than in forests. Therefore, the poor availability of resources might lead to no obvious changes in the relative abundance of Basidiomycota among the four ecosystems in arid and semi-arid temperate grasslands.

\subsection{Plant community composition as the main driver of fungal beta diversity}

It was apparent across the range of statistical analyses we applied that plant species richness was the best predictor for fungal alpha diversity (fungal richness), even after controlling for soil properties and climatic factors, which supported our first hypothesis. However, our study was inconsistent with recent studies reporting no significant relationship between plant and fungal alpha diversity across global grasslands (Tedersoo et al., 2014; Prober et al., 2015), but corroborated the finding that certain fungal groups responded strongly to plant diversity on a landscape scale (Tedersoo and Bahram, 2016). We attribute this discrepancy to the differences in spatial sales, which may strengthen the differences in the environmental factors driving plant and fungal alpha diversity patterns. In the study of Prober et al. (2015), the environmental drivers of plant alpha diversity were generally different from fungal alpha diversity at global scales. In contrast, the plant and fungal alpha diversity was driven by the similar environmental factors (Table 1) in this study at regional scales. Higher plant richness is usually associated with higher plant productivity due to niche complementarity and greater resource supply (Tilman et al., 2001; Zak et al., 2003). In our study it may have been the case that increases in plant richness resulted in increases in the pools (mostly carbon) that were available to microorganisms, and thus favored higher fungal richness (Lange et al., 2015). Apart from plant richness, both SEM and correlation analysis revealed strong effects of MAP and soil parameters on soil fungal richness, suggesting a strong niche effect and species effect on soil fungi. Consistent with this study, Tedersoo and Bahram, (2016) found that individual tree species and soil resources have strong effects on taxonomic richness of soil fungi.

We also observed that fungal beta diversity was significantly and positively correlated with plant beta diversity, even after excluding the effect of environmental factors and geographical distance. Variation partitioning analysis further suggested that plant community composition plays more important roles in influencing soil fungal communities in arid and semi-arid grasslands of northern China. As stated above, the strong coupling of plant-fungal beta diversity was possibly driven by the similar environmental factors (Table 2; Table S5, Table S6) in this study. From this point of view, our study confirms the important influence of plant community composition on soil fungal communities as previously revealed at a global scale (Prober et al., 2015). The observed relationships between fungal and plant alpha and beta diversity were possibly due to the host specificity of functional fungal groups (Chen et al., 2014b; Zeilinger et al., 2015). For instance, mycorrhizal fungi and fungal pathogens are tightly linked to plants by forming symbiotic and parasitic relationships (Holah and Alexander, 1999; Vandenkoornhuyse et al., 2003; Gao et al., 2013). Holah and Alexander (1999) confirmed that soil pathogenic fungi have the potential to affect the co-existence of two tallgrass prairie species. Therefore, changes in host plant community composition in space may regulate specific soil fungal compositions. The feedback between plants and fungi or increased resource availability for fungi was another important determinant of soil fungal diversity (Waldrop et al., 2006; Bever et al., 2013). Above-ground plant community composition is expected to affect soil fungal community composition via plant residues and rhizodeposition (Waldrop et al., 2006). Greater plant diversity would increase the variety of organic substrates entering soil, thereby increasing the number of niches to be filled by a greater array of heterotrophic fungi (Waldrop et al., 2006). It was reported that more plant detritus might be available as energy to fungi in plant species rich areas, due to more aboveground net primary production (ANPP) resulting from niches complementarity and positive interactions (Tilman et al., 2001). Higher levels of plant detritus production would increase the supply of organic substrates, thereby increasing fungal diversity (Waldrop et al., 2006). Differences in litter composition, like cellulose and lignin contents, would also result in differences in the community composition of decomposers (e.g. fungi) (Sterkenburg et al., 2015).

\subsection{Non-negligible roles of abiotic factors and geographical distance in determining fungal community structure}

Climatic factors such as MAP and MAT significantly correlated with soil fungal alpha and beta diversity, which strongly supported our second hypothesis (Table 2, Table S6). The results are in accordance with recent studies showing that fungal community compositions could be predicted by climatic factors (Tedersoo et al., 2014; Timling et al., 2014). For instance, Tedersoo et al. (2014) found that MAP was the strongest predictor of total fungal richness at the global scale. Precipitation or water availability plays key roles in regulating ecosystem functioning, especially in arid and semiarid areas like temperate grasslands in northern China (Yang et al., 2012). It was reported that MAP is the primary factor affecting aboveground net primary production of the plant community (Bai et al., 2008), which in turn affects the quantity and quality of plant residue input to below-ground fungal communities. MAT was also a significant climatic factor for plant and soil fungal communities in this study, although MAT played a less important role than MAP in shaping soil fungal diversity. This finding is consistent with recent reports suggesting fungal beta diversity can be predicted by temperature over broad scales (Prober et al., 2015; Zhou et al., 2016), indicating that fundamental concepts such as metabolic theory may be suitable for soil fungi as well as plants.

We found that geographical distance was another important predictor of soil fungal community structures but explained the lowest fraction compared with plant communities and abiotic factors in this study, indicating that dispersal limitation might be less important than contemporary environmental conditions in structuring fungal communities at regional scale. We suggest that fungi have limited capacity for long distance dispersal at regional scales, although microbes have higher potential for a cosmopolitan distribution because of the small body size and large numbers of propagules (Martiny et al., 2006). Dispersal limitation is also substantial for the geographical distribution of fungi over the continental scale (Sato et al., 2012), as there are very few Basidiomycete species such as ectomycorrhizal and saprotrophic fungi shared between temperate Asia and temperate Europe.

\section{Conclusions}

In conclusion, we conducted a comprehensive study to investigate the biogeographical distribution patterns of soil fungal communities across arid and semi-arid grasslands at regional scales. We were able to simultaneously examine plant community composition, abiotic factors, and geographical distance along a $4000-\mathrm{km}$ transect in temperate grasslands of northern China. In agreement with recent reports on global drylands and temperate grasslands (Maestre et al., 2015; Prober et al., 2015), fungal communities in the arid and semiarid grassland of northern China were dominated by Ascomycota. Furthermore, fungal richness and community composition were strongly correlated with alpha and 
beta diversity of plant communities, respectively. This is possibly mediated by the similarity in the biographical drivers of alpha and beta diversity for fungi and plants. The consistency of these patterns in plant-fungal diversity indicated that previous findings that plant diversity predicts beta but not alpha diversity of soil fungi (Prober et al., 2015) may not be a general pattern over broad scales. Finally, the biogeographic patterns of soil fungal communities could be predominantly explained by plant community composition, and then by abiotic factors and spatial distance. Together with the two comprehensive studies at global scale (Maestre et al., 2015; Prober et al., 2015), plant diversity was shown to play key roles in shaping soil fungal community structure over large spatial scales. Our study fills a gap in our understanding of soil fungal community composition at regional scales in arid and semiarid grasslands, and these findings strengthens our knowledge about the diversity and ecology of fungi in terrestrial ecosystems.

\section{Acknowledgments}

We are grateful to all the members of the sampling campaign team from the Research Center for Eco-Environmental Sciences, Chinese Academy of Sciences for their assistance during field sampling. This research was supported by National Key Research and Development Program of China (2016YFC0500702), National Natural Science Foundation of China (41371264), and a Joint Project of the Ministry of Environmental Protection of China and the Chinese Academy of Sciences (STSN-21-04).

\section{Appendix A. Supplementary data}

Supplementary data related to this article can be found at http:// dx.doi.org/10.1016/j.soilbio.2017.02.015.

\section{References}

Abarenkov, K., Nilsson, R.H., Larsson, K.H., Alexander, I.J., Eberhardt, U., Erland, S., et al., 2010. The UNITE database for molecular identification of fungi-recent updates and future perspectives. New Phytologist 186, 281-285.

Bai, Y.F., Wu, J.G., Xing, Q., Pan, Q.M., Huang, J.H., Yang, D.L., Han, X.G., 2008. Primary production and rain use efficiency across a precipitation gradient on the Mongolia plateau. Ecology 89, 2140-2153.

Bardgett, R.D., van der Putten, W.H., 2014. Belowground biodiversity and ecosystem functioning. Nature 515, 505-511.

Bever, J.D., Broadhurst, L.M., Thrall, P.H., 2013. Microbial phylotype composition and diversity predicts plant productivity and plant-soil feedbacks. Ecology Letters $16,167-174$.

Byrnes, J.E.K., Gamfeldt, L., Isbell, F., Lefcheck, J.S., Griffin, J.N., Hector, A. Cardinale, B.J., Hooper, D.U., Dee, L.E., Duffy, J.E., 2014. Investigating the relationship between biodiversity and ecosystem multifunctionality: challenges and solutions. Methods in Ecology and Evolution 5, 111-124.

Caporaso, J.G., Kuczynski, J., Stombaugh, J., Bittinger, K., Bushman, F.D., Costello, E.K., et al., 2010. QIIME allows analysis of high-throughput community sequencing data. Nature Methods 7, 335-336.

Caporaso, J.G., Lauber, C.L., Walters, W.A., Berg-Lyons, D., Lozupone, C.A., Turnbaugh, P.J., et al., 2011. Global patterns of $16 \mathrm{~S}$ rRNA diversity at a depth of millions of sequences per sample. Proceeding of the National Academy of Sciences of the United States of America 108, 4516-4522.

Chase, M.W., Reveal, J.L., 2009. A phylogenetic classification of the land plants to accompany APG III. Botanical Journal of the Linnean Society 161, 122-127.

Chen, D.M., Mi, J., Chu, P.F., Cheng, J.H., Zhang, L.X., Pan, Q.M., Xie, Y.C., Bai, Y.F. 2014a. Patterns and drivers of soil microbial communities along a precipitation gradient on the Mongolian Plateau. Landscape Ecology 30, 1669-1682.

Chen, Y.L., Zhang, X., Ye, J.S., Han, H.Y., Wan, S.Q., Chen, B.D., 2014b. Six-year fertilization modifies the biodiversity of arbuscular mycorrhizal fungi in a temperate steppe in Inner Mongolian. Soil Biology and Biochemistry 69, $371-381$.

Clemmensen, K.E., Finlay, R.D., Dahlberg, A., Stenlid, J., Wardle, D.A., Lindahl, B.D., 2015. Carbon sequestration is related to mycorrhizal fungal community shifts during long-term succession in boreal forests. New Phytologist 205, 1525-1536.

Dai, A., 2013. Increasing drought under global warming in observations and models. Nature Climate Change 3,52-58.

Dray, S., Legendre, P., Peres-Neto, P.R., 2006. Spatial modelling: a comprehensive framework for principal coordinate analysis of neighbor matrices (PCNM). Ecological Modelling 196, 483-493.
Easterling, D.R., Meehl, G., Parmesan, C., Changnon, S.A., Karl, T.R., Mearns, L.O., 2000. Climate extremes: observations, modeling, and impacts. Science 289, 2068-2074.

Edgar, R.C., 2010. Search and clustering orders of magnitude faster than BLAST Bioinformatics 26, 2460-2461.

Fierer, N., Jackson, R.B., 2006. The diversity and biogeography of soil bacterial communities. Proceeding of the National Academy of Sciences of the United States of America 103, 626-631.

Gao, C., Shi, N., Liu, Y., Peay, K.G., Zheng, Y., Ding, Q., Mi, X.C., Ma, K.P., Wubet, T. Buscot, F., Guo, L.D., 2013. Host plant genus-level diversity is the best predictor of ectomycorrhizal fungal diversity in a Chinese subtropical forest. Molecular Ecology 22, 3403-3414.

Gardes, M., Bruns, D., 1993. ITS primers with enhanced specificity for basidiomycetes-application to the identification of mycorrhizae and rusts. Molecular Ecology 2, 113-118.

Geremia, R.A., Puscas, M., Zinger, L., Bonneville, J.M., Choler, P., 2016. Contrasting microbial biogeographical patterns between anthropogenic subalpine grasslands and natural alpine grasslands. New Phytologist 209, 1196-1207.

Goslee, S.C., Urban, D.L., 2007. The ecodist package for dissimilarity-based analysis of ecological data. Journal of Statistical Software 22, 1-19.

Henrik, N.R., Tedersoo, L., Lindahl, B.D., Kjøller, R., Carlsen, T., Quince, C., Abarenkov, K., Pennanen, T., Stenlid, J., Bruns, T., Larsson, K.H., Kõljalg, U. Kauserud, H., 2011. Towards standardization of the description and publication of next-generation sequencing datasets of fungal communities. New Phytologist 191, 314-318.

Hiiesalu, I., Pärtel, M., Davison, J., Gerhold, P., Metsis, M., Moora, M., Öpik, M. Vasar, M., Zobel, M., Wilson, S.D., 2014. Species richness of arbuscular mycorrhizal fungi: associations with grassland plant richness and biomass. New Phytologist 203, 233-244.

Högberg, M.N., Bääth, E., Nordgren, A., Arnebrant, K., Högberg, P., 2003. Contrasting effects of nitrogen availability on plant carbon supply to mycorrhizal fungi and saprotrophs - a hypothesis based on field observations in boreal forest. New Phytologist 160, 225-238.

Holah, J., Alexander, H., 1999. Soil pathogenic fungi have the potential to affect the co-existence of two tallgrass prairie species. Journal of Ecology 87, 598-608.

Hooper, D., Coughlan, J., Mullen, M., 2008. Structural equation modelling: guidelines for determining model fit. Electronic Journal of Business Research Methods 6, 53-60.

Hudson, C.M., Kirton, E., Hutchinson, M.I., Redfern, J.L., Simmons, B., Ackerman, E. Singh, S., Williams, K.P., Natvig, D.O., Powell, A.J., 2015. Lignin-modifying processes in the rhizosphere of arid land grasses. Environmental Microbiology 17, 4965-4978.

Klironomos, J.N., Zobel, M., Tibbett, M., Stock, W.D., Rillig, M.C., Parrent, J.L., Moora, M., Koch, A.M., Facelli, J.M., Facelli, E., Dickie, I.A., Bever, J.D., 2011. Forces that structure plant communities: quantifying the importance of the mycorrhizal symbiosis. New Phytologist 189, 366-337.

Lange, M., Eisenhauer, N., Sierra, C.A., Bessler, H., Engels, C., Griffiths, R.I., et al., 2015. Plant diversity increases soil microbial activity and soil carbon storage. Nature Communications 6, 6707.

Lauber, C.L., Hamady, M., Knight, R., Fierer, N., 2009. Pyrosequencing-based assessment of soil pH as a predictor of soil bacterial community structure at the continental scale. Applied and Environmental Microbiology 75, 5111-5120.

Maestre, F.T., Delgado-Baquerizo, M., Jeffries, T.C., Eldridge, D.J., Ochoa, V., Gozalo, B. Quero, J.L., García-Gómez, M., Gallardo, A., Ulrich, W., Bowker, M.A. Arredondo, T., Barraza-Zepeda, C., Bran, D., Florentino, A., Gaitán, J., Gutiérrez, J.R., Huber-Sannwaldi, E., Jankju, M., Mau, R.L., Miriti, M., Naseri, K. Ospina, A., Stavi, I., Wang, D., Woods, N.N., Yuan, X., Zaady, E., Singh, B.K., 2015 Increasing aridity reduces soil microbial diversity and abundance in global drylands. Proceeding of the National Academy of Sciences of the United States of America 112, 15684-15689.

Martiny, J.B., Bohannan, B.J., Brown, J.H., Colwell, R.K., Fuhrman, J.A., Green, J.L., et al., 2006. Microbial biogeography: putting microorganisms on the map. Nature Reviews Microbiology 4, 102-112.

Millard, P., Singh, B., 2010. Does grassland vegetation drive soil microbial diversity? Nutrient Cycling in Agroecosystems 88, 147-158.

Murphy, J., Riley, J.P., 1962. A modified single solution method for the determination of phosphate in natural waters. Analytica Chimica Acta 27, 31-36.

Ni, J., Zhang, X.S., 2000. Climate variability, ecological gradient and the Northeast China Transect (NECT). Journal of Arid Environments 46, 313-325.

Peay, K.G., Baraloto, C., Fine, P.V.A., 2013. Strong coupling of plant and fungal community structure across western Amazonian rainforests. The ISME Journal 7. 1852-1861.

Pellissier, L., Niculita-Hirzel, H., Dubuis, A., Pagni, M., Guex, N., Ndiribe, C., et al., 2014. Soil fungal communities of grasslands are environmentally structured at a regional scale in the Alps. Molecular Ecology 23, 4274-4290.

Porras-Alfaro, A., Herrera, J., Natvig, D.O., Lipinski, K., Sinsabaugh, R.L., 2011. Diversity and distribution of soil fungal communities in a semiarid grassland. Mycologia 103, 10-21.

Porras-Alfaro, A., Herrera, J., Natvig, D.O., Sinsabaugh, R.L., 2007. Effect of long-term nitrogen fertilization on mycorrhizal fungi associated with a dominant grass in a semiarid grassland. Plant and Soil 296, 65-75.

Prober, S.M., Leff, J.W., Bates, S.T., Borer, E.T., Firn, J., Harpole, W.S., et al., 2015. Plant diversity predicts beta but not alpha diversity of soil microbes across grasslands worldwide. Ecology Letters 18, 85-95.

R Development Core Team, 2013. R: a Language and Environment for Statistica 
Computing. R Foundation for Statistical Computing, Vienna.

Sato, H., Tsujino, R. Kurita, K., Yokoyama, K., Agata, K., 2012. Modelling the globa distribution of fungal species: new insights into microbial cosmopolitanis. Molecular Ecology 21, 5599-5612.

Schoch, C.L., Seifert, K.A., Huhndorf, S., Vincent, R., Spouge, J.L., Levesque, C.A., et al., 2012. Nuclear ribosomal internal transcribed spacer (ITS) region as a universal DNA barcode marker for Fungi. Proceeding of the National Academy of Sciences of the United States of America 109, 6241-6246.

Sterkenburg, E., Bahr, A., Durling, M.B., Clemmensen, K.E., Lindal, B., 2015. Changes in fungal communities along a boreal forest soil fertility gradient. New Phytologist 207, 1145-1158.

Taylor, D.L., Hollingsworth, T.N., Mcfarland, J.W., Lennon, N.J., Nusbaum, C., Ruess, R.W., 2014. A first comprehensive census of fungi in soil reveals both hyperdiversity and fine-scale niche partitioning. Ecological Monographs 84, $3-20$.

Tedersoo, L., Bahram, M., 2016. Tree diversity and species identity effects on soil fungi, protists and animals are context dependent. The ISME Journal 10 , $346-362$.

Tedersoo, L., Bahram, M., Põlme, S., Kõljalg, U., Yorou, N.S., Wijesundera, R., et al., 2014. Global diversity and geography of soil fungi. Science 346, 1078 .

Tilman, D., Reich, P.B., Knops, J., Wedin, D., Mielke, T., Lehman, C., 2001. Diversity and productivity in a long-term grassland experiment. Science 294, 843-845.

Timling, I., Walker, D.A., Nusbaum, C., Lennnon, N.J., Taylor, D.L., 2014. Rich and cold: diversity, distribution and drivers of fungal communities in patterned-ground ecosystems of the North American Arctic. Molecular Ecology 23, 3258-3272.

Van der Heijden, M.G.A., Bardgett, R.D., Van Straalen, N.M., 2008. The unseen majority: soil microbes as drivers of plant diversity and productivity in terrestrial ecosystems. Ecology Letters 11, 296-310.

Van der Heijden, M.G.A., Klironomos, J.N., Ursic, M., Moutoglis, P., StreitwolfEngel, R., Boller, T., et al., 1998. Mycorrhizal fungal diversity determines plant biodiversity, ecosystem variability and productivity. Nature 396, 72-75.

Vandenkoornhuyse, P., Ridgway, K.P., Watson, I.J., Fitter, A.H., Young, J.P.W., 2003. Co-existing grass species have distinctive arbuscular mycorrhizal communities. Molecular Ecology 12, 3085-3095.

Vargas-Gastélum, L., Romero-Olivares, A.L., Escalante, A.E., Rocha-Olivares, A.,
Brizuela, C., Riquelme, M., 2015. Impact of seasonal changes on fungal diversity of a semi-arid ecosystem revealed by 454 pyrosequencing. FEMS Microbiology Ecology 91 fiv044.

Waldrop, M.P., Zak, D.R., Blackwood, C.B., Curtis, C.D., Tilman, D., 2006. Resource availability controls fungal diversity across a plant diversity gradient. Ecology Letters 9, 1127-1135.

Walkley, A., 1947. A critical examination of a rapid method for determining organic carbon in soils-effect of variations in digestion conditions and of inorganic soil constituents. Soil Science 63, 251-264.

Wang, X.B., Van Nostrand, J.D., Deng, Y., Lü, X.T., Wang, C., Zhou, J.Z., et al., 2015 Scale-dependent effects of climate and geographic distance on bacterial diversity patterns across northern China's grasslands. FEMS Microbiology Ecology 91 fiv133.

Wardle, D.A., 2006. The influence of biotic interactions on soil biodiversity. Ecology Letters 9, 870-886.

White, T.J., Bruns, T., Lee, S., Taylor, J.W., 1990. Amplification and direct sequencing of fungal ribosomal RNA genes for phylogenetics. In: Innis, M.A., Gelfand, D.H., Sninsky, J.J., White, T.J. (Eds.), PCR Protocols: a Guide to Methods and Applications. Academic Press, Inc., New York, pp. 315-322.

Wubet, T., Christ, S., Schöning, I. Boch, S., Gawlich, M., Schnabel, B., et al., 2012. Differences in soil fungal communities between European Beech (Fagus sylvatica L.) dominated forests are related to soil and understory Vegetation. PLoS ONE 7, e47500.

Yang, H.J., Li, Y., Wu, M.Y., Zhang, Z., Li, L.H., Wan, S.O., 2012. Plant community responses to nitrogen addition and increased precipitation: the importance of water availability and species traits. Global Change Biology 17, 2936-2944.

Zak, D.R., Holmes, W.E., White, D.C., Peacock, A.D., Tilman, D., 2003. Plant diversity, soil microbial communities, and ecosystem function: are there any links? Ecology 84, 2042-2050.

Zeilinger, S., Gupta, V.K., Dahms, T.E.S., Silva, R.N., Singh, H.B., Upadhyay, R.S., et al., 2015. Friends or foes? Emerging insights from fungal interactions with plants. FEMS Microbiology Reviews 40, 182-207.

Zhou, J.Z., Deng, Y., Shen, L.N., Wen, C.Q., Yan, Q.Y., Ning, D.L., et al., 2016. Temperature mediates continental-scale diversity of microbes in forest soils. Nature Communications 7, 12083. 